Original Research Article

\title{
Cost variation analysis of antihypertensive drugs acting through renin angiotensin aldosterone axis modulation
}

\author{
Manju K. Nair ${ }^{1 *}$, Neha M. S. ${ }^{2}$
}

\begin{abstract}
${ }^{1}$ Department of Pharmacology, Government Medical College, Thiruvananthapuram, Kerala, India

${ }^{2}$ K.S. Hegde Medical Academy, Deralkatte, Mangalore,

Karnataka, India
\end{abstract}

Received: 19 March 2017

Accepted: 25 March 2017

*Correspondence to:

Dr. Manju K. Nair,

Email:

manjusunjith@gmail.com

Copyright: () the author(s), publisher and licensee Medip Academy. This is an openaccess article distributed under the terms of the Creative Commons Attribution NonCommercial License, which permits unrestricted noncommercial use, distribution, and reproduction in any medium, provided the original work is properly cited.

\begin{abstract}
Background: Several brands of antihypertensive drugs are available in the Indian market with huge price variations. This study was undertaken to find out the percentage cost variation and cost ratio of antihypertensive drugs acting through renin angiotensin aldosterone axis modulation.

Methods: Costs of different brands of renin angiotensin aldosterone axis modulatory drugs with antihypertensive action for the same dosage form and strength were found out using current index of medical specialties-134, JulyOctober 2016. The maximum and minimum price of different brands of each drug was noted. Data was entered in Microsoft excel 2010. Percentage cost variation and cost ratio was calculated for each drug.

Results: 16 antihypertensive drugs were analysed. Most of them were tablets. Ramipril and Valsartan were available as capsules also. Among tablets, percentage cost variation was highest for Atenolol $12.5 \mathrm{mg}(683.93 \%)$ and least for Bisoprolol $2.5 \mathrm{mg}$ (3.6538\%). Valsartan capsules (160 mg) had no difference in the costs between the available 2 brands. Cost ratio ranged from 1.04 to 7.84 among the tablet form of drugs.

Conclusions: There is a huge difference in the cost of antihypertensive drugs manufactured by different companies in the same strength and dosage form. To promote rational drug use and cost effective therapy, it is essential to create an awareness among clinicians regarding the availability of multiple brands for these drugs and the discrepancies in their costs.
\end{abstract}

Keywords: Antihypertensive drugs, Brands, Cost ratio, Percentage cost variation, Tablet

\section{INTRODUCTION}

Hypertension is a major contributor to various cardiovascular diseases and can lead to increased morbidity and mortality. In India, the prevalence of hypertension varies from 17 to $21 \%$ and it attributes for $10 \%$ of all deaths. ${ }^{1-4}$ In fact, studies reveal that prevalence of hypertension in the last six decades has increased from $2 \%$ to $25 \%$ among urban residents and from $2 \%$ to $15 \%$ among the rural residents in India. ${ }^{5}$ This disease requires long term treatment, generating higher health care expenses. The Pharmaceutical Industry has flooded the Indian markets with several brands of antihypertensive drugs with variations in the selling price of different brands of the same formulation. The expenditure incurred for antihypertensive drug therapy in India is about $64 \% .^{6}$ Higher cost of medicines and longer duration of therapy can impose higher economic burden, thereby reducing patient compliance to therapy.

Normally, the auto regulation of blood pressure in human beings is achieved by baroreceptor reflexes, renin angiotensin aldosterone axis (RAA axis) and release of local hormones from vascular endothelium like nitric oxide and endothelin. ${ }^{7}$ Therefore, drugs modulating RAA axis can serve as effective antihypertensive drugs. Angiotensin converting enzyme inhibitors (E.g. Captopril, Enalapril, Lisinopril etc.), Angiotensin 
receptor antagonists (Eg. Losartan, Candesartan, Telmisartan etc.), Inhibitors of Renin release (Eg. Beta blockers, Alpha methyl dopa, Clonidine), Renin inhibitors (Eg. Aliskiren) and Aldosterone antagonists (Eg. Eplerenone) are few examples of RAA axis modulators having antihypertensive action. ${ }^{7}$ As these groups of drugs are widely prescribed in the treatment of hypertension, to promote rational drug use, it is necessary to understand the availability of different brands of these drugs, their dosage forms, the strengths in which they are available and their retail price in market. Hence, this study was undertaken to find out the price differences between the various brands of the same RAA axis modulator with antihypertensive action, manufactured by different companies in India. This will help to reduce the prescription costs and thereby enhance therapeutic compliance in clinical practice.

\section{METHODS}

Angiotensin converting enzyme inhibitors, Angiotensin receptor antagonists, Beta blockers and Alpha methyl dopa were selected for the study as they exerted antihypertensive action by RAA axis modulation. The cost of different brands of these drugs produced by different manufacturers, for the same dosage form and strength were found out using "Current Index of Medical Specialities (CIMS)-134, July-October 2016 (Update 3). 8,9 The cost was expressed in Indian rupee (INR) per ten tablets /capsules /other oral dosage forms for different brands of these drugs in CIMS. For atenolol, cost per 14 tablets were noted. Drugs produced by a single pharmaceutical company and drugs whose cost information was not available in CIMS were excluded from the study.

Eplerenone and Aliskiren were excluded as their costs were not available. Captopril, Fosinopril, Irbesartan, Oxprenolol and Clonidine were excluded as only single brands in the same strength were available. Only oral dosage forms were considered for cost analysis. Drug combinations were not included. The maximum and minimum price of different brands of each drug for the same dosage form and strength were noted. The percentage cost variation and cost ratio was then calculated for each drug as follows: ${ }^{10-15}$

Percentage cost variation $=$ Maximum cost of the brand Minimum cost of the brand / Minimum cost of the brand) $\mathrm{x} 100$.

Cost ratio is the ratio between the cost of the most expensive and the least expensive formulation of the drug. It helps in determining how many times the most expensive formulation is costlier than the least expensive formulation of the same drug.

Cost ratio $=$ Maximum cost of the brand / Minimum cost of the brand. ${ }^{4,11}$

\section{Statistical analysis}

Data collected was entered in Microsoft excel 2010 and analysed. Percentage cost variation and cost ratio was calculated for each drug.

\section{RESULTS}

In this study, 16 antihypertensive drugs were analysed. Of these 16 drugs, 3 were Angiotensin converting enzyme inhibitors (ACE inhibitors), 5 were Angiotensin receptor blockers (ARBs), 7 were Beta blockers and 1 was Alpha methyl dopa (Table 1 and 2). Among the ACE inhibitors, 16 brands were available for Tab. Ramipril $2.5 \mathrm{mg}, 14$ brands for Tab. Ramipril $5 \mathrm{mg}, 11$ brands for Tab Enalapril $5 \mathrm{mg}$ and 10 brands for Tab Enalapril $2.5 \mathrm{mg}$. All the other ACE inhibitors were available in less than 10 different brands. Among the ACE inhibitors, Ramipril was available as tablets and capsules in 4 different strengths (1.25 mg, 2.5mg, $5 \mathrm{mg}$ and $10 \mathrm{mg}$ ). Among ARBs, 39 brands were seen for Tab Telmisartan $40 \mathrm{mg}$, 22 brands for Tab Telmisartan $20 \mathrm{mg}, 29$ brands for Tab Losartan $50 \mathrm{mg}$ and 26 brands for Tab Losartan $25 \mathrm{mg}$. Rest of the ARBs were available in less than 20 different brands. Film coated tablets (FC Tab) of Losartan were available in $25 \mathrm{mg}$ and $50 \mathrm{mg}$ strengths. Valsartan was available as capsules also. There was no cost difference between the 2 brands of Valsartan capsules containing $160 \mathrm{mg}$ of the drug (Table 1). Tab Atenolol $50 \mathrm{mg}$ had the maximum number of brands (19) among the Beta blockers. There were 16 brands each of Tab Atenolol 25 mg and Extended Release Tab (ER Tab) Metoprolol 25 mg. 17 different brands were available for ER Tab Metoprolol $50 \mathrm{mg}$. Metoprolol was available as tablets, capsules and ER tablets. Propranolol $40 \mathrm{mg}$ was available as 5 different brands of tablets and 2 different brands of sustained release tablets. Tab Alpha methyl dopa, $250 \mathrm{mg}$ was available in 2 different brands (Table 2).

Percentage cost variation among ACE inhibitors was maximum for Tab Lisinopril $2.5 \mathrm{mg}(273.3 \%)$ with a cost ratio of 3.73 and least for Tab Lisinopril $20 \mathrm{mg}$ (39.419\%) with a cost ratio of 1.39 . Cap Ramipril $2.5 \mathrm{mg}$ showed a percentage cost variation of $115.52 \%$ with a cost ratio of 2.16. Among ARBs, it was maximum for Tab Telmisartan $20 \mathrm{mg}(322.22 \%)$ with a cost ratio of 4.22 and least for Tab Candesartan $4 \mathrm{mg}(22.718 \%)$ with a cost ratio of 1.23. The cost ratio of FC tab Losartan $25 \mathrm{mg}$ and $50 \mathrm{mg}$ were 1.2 and 1.32 respectively (Table 1$)$. In the Beta blocker group, Tab Atenolol 12.5 mg had the highest percentage cost variation $(683.93 \%)$ with a cost ratio 7.84 and it was least for Tab Bisoprolol $2.5 \mathrm{mg}$ (3.6538\%) with a cost ratio of 1.04 . Sustained release tablet of Propranolol $(40 \mathrm{mg})$ showed a percentage cost variation of $5.1282 \%$ with a cost ratio of 1.05 . Among the extended release tablets, Metoprolol $50 \mathrm{mg}$ showed a percentage cost variation of $133.33 \%$. As capsules, Metoprolol $25 \mathrm{mg}$ showed a high percentage cost variation of $293.63 \%$. Alpha methyldopa was available as $250 \mathrm{mg}$ tablets in 2 different brands and they showed a percentage cost variation of $10.887 \%$ with a cost ratio of 1.11 (Table 2 ). 
Table 1: Percentage cost variation and cost ratio of ACE inhibitors and angiotensin receptor antagonists.

\begin{tabular}{|c|c|c|c|c|c|c|}
\hline SN & Drug (strength) & $\mathbf{n}$ & Max. cost & Min. cost & $\% \mathrm{CV}$ & $\mathbf{C R}$ \\
\hline \multirow[t]{3}{*}{1} & Tab Enalapril (2.5 mg) & 10 & 22.6 & 8.8 & 156.82 & 2.57 \\
\hline & Tab Enalapril (5 mg) & 11 & 36.84 & 15 & 145.6 & 2.46 \\
\hline & Tab Enalapril (10 mg) & 9 & 59.3 & 27.75 & 113.69 & 2.14 \\
\hline \multirow[t]{4}{*}{2} & Tab Lisinopril (2.5 mg) & 8 & 37.33 & 10 & 273.3 & 3.73 \\
\hline & Tab Lisinopril (5 mg) & 9 & 69 & 25.1 & 174.9 & 2.75 \\
\hline & Tab Lisinopril (10 mg) & 9 & 122.3 & 45.45 & 169.09 & 2.69 \\
\hline & Tab Lisinopril (20 mg) & 2 & 134.4 & 96.4 & 39.419 & 1.39 \\
\hline \multirow[t]{8}{*}{3} & Tab Ramipril (1.25 mg) & 8 & 40.77 & 13.2 & 208.86 & 3.09 \\
\hline & Tab Ramipril (2.5 mg) & 16 & 73.53 & 25.5 & 188.35 & 2.88 \\
\hline & Tab Ramipril (5 mg) & 14 & 123.9 & 46 & 169.35 & 2.69 \\
\hline & Tab Ramipril (10 mg) & 5 & 179.3 & 92.8 & 93.211 & 1.93 \\
\hline & Cap Ramipril (1.25 mg) & 5 & 32.11 & 18.4 & 74.511 & 1.75 \\
\hline & Cap Ramipril (2.5 mg) & 8 & 62.5 & 29 & 115.52 & 2.16 \\
\hline & Cap Ramipril (5 mg) & 8 & 99.95 & 55 & 81.727 & 1.82 \\
\hline & Cap Ramipril (10 mg) & 3 & 133.8 & 89.9 & 48.832 & 1.49 \\
\hline \multirow[t]{4}{*}{4} & Tab Losartan (25mg) & 26 & 45.1 & 13.2 & 241.67 & 3.42 \\
\hline & Tab Losartan (50mg) & 29 & 93.85 & 27.5 & 241.27 & 3.41 \\
\hline & FC Tab Losartan (25mg) & 4 & 34 & 28.25 & 20.354 & 1.2 \\
\hline & FC Tab Losartan (50mg) & 4 & 68.5 & 52 & 31.731 & 1.32 \\
\hline \multirow[t]{2}{*}{5} & Tab Candesartan (4 mg) & 2 & 34.95 & 28.48 & 22.718 & 1.23 \\
\hline & Tab Candesartan (8 mg) & 2 & 61.8 & 46.37 & 33.276 & 1.33 \\
\hline \multirow[t]{3}{*}{6} & Tab Olmesartan (10 mg) & 4 & 53.29 & 39 & 36.641 & 1.37 \\
\hline & Tab Olmesartan (20 mg) & 16 & 87.92 & 46 & 91.13 & 1.91 \\
\hline & Tab Olmesartan (40 mg) & 18 & 149 & 75 & 98.667 & 1.99 \\
\hline \multirow[t]{3}{*}{7} & Tab Telmisartan (20 mg) & 22 & 76 & 18 & 322.22 & 4.22 \\
\hline & Tab Telmisartan (40 mg) & 39 & 86.1 & 28 & 207.5 & 3.08 \\
\hline & Tab Telmisartan (80 mg) & 19 & 134 & 89 & 50.562 & 1.51 \\
\hline \multirow[t]{2}{*}{8} & Cap Valsartan (80 mg) & 2 & 69.14 & 69 & 0.2029 & 1 \\
\hline & Cap Valsartan (160 mg) & 2 & 130 & 130 & 0 & 1 \\
\hline
\end{tabular}

( $\mathrm{n}$ - Number of brands, Max cost- Maximum Cost per 10 drugs, Min cost -Minimum Cost per 10 drugs, \% CV- Percentage cost variation, CR-Cost ratio, Tab- Tablet, Cap-Capsule, FC tab-Film coated tablet)

\section{DISCUSSION}

As the pharmaceutical companies have flooded the Indian market with approximately $60000-70000$ products, scope for price variations are considerably high. ${ }^{16}$ Drug cost is an important determinant of compliance to therapy. Government can frame policies to keep the cost of drugs low. The National Pharmaceutical pricing authority is a government regulatory agency that controls the prices of pharmaceutical drugs in India. Drug price control order (DPCO) issued by the government of India fixes the prices of drugs. Drugs in the DPCO list cannot be sold at a price higher than that fixed by the government. ${ }^{17}$ Unfortunately, India has less than one fifth of its medicines under price control. The government should take measures to bring more drugs under the ambit of price control to ensure affordability.

In this study, Angiotensin converting enzyme inhibitors, Angiotensin receptor antagonists, Beta blockers and Alpha methyl dopa were analysed. Most of them were available as tablets in different strengths. Ramipril and
Valsartan were available as Capsules also. Multiple number of brands were available for most of the drugs. In this study, the prices of most of the antihypertensive brands had a percentage price variation above $100 \%$. This is not a favourable situation for patients as it can lead to economic overload and noncompliance to treatment. Tab. Lisinopril $2.5 \mathrm{mg}$ had the highest percentage cost variation $(273.3 \%)$ among ACE inhibitors. The most expensive formulation of this drug was 3.73 times costlier than its least expensive formulation. However, Tab. Lisinopril $20 \mathrm{mg}$ (39.419\%) was the ACE inhibitor with least percentage cost variation. Ramipril $2.5 \mathrm{mg}$ capsules had a higher percentage cost variation when compared to other strengths of Cap. Ramipril. Film coated tablets of Losartan $25 \mathrm{mg}$ and $50 \mathrm{mg}$ were available in 4 brands each. However, the percentage cost variation was higher for FC Tab losartan $50 \mathrm{mg}$. Telmisartan $20 \mathrm{mg}$ tablets showed very high percentage cost variation (322.22\%). Valsartan was available as capsules in the strengths $80 \mathrm{mg}$ and $160 \mathrm{mg}$. There was a difference of only 14 paise between the 2 brands of 80 mg Valsartan capsules resulting in a percentage cost 
variation of just $0.2029 \%$. There was no cost difference between the 2 brands of $160 \mathrm{mg}$ valsartan capsules. Tablet Atenolol $12.5 \mathrm{mg}$ had a high percentage cost variation (683.93\%). The cost ratio between the 2 brands of SR tab Propranolol was 1.05. High percentage cost variation was seen for extended release tablets of Metoprolol $50 \mathrm{mg}(133.33 \%)$ and Metoprolol $25 \mathrm{mg}$ capsules $(293.63 \%)$. The percentage cost variation of Tab Alpha methyl dopa $250 \mathrm{mg}$ was $10.887 \%$.

Table 2: Percentage cost variation and cost ratio of antihypertensive drugs which modulate RAA axis through inhibition of renin release (beta blockers and alpha methyl dopa).

\begin{tabular}{|c|c|c|c|c|c|}
\hline Drug (strength) & $\mathbf{n}$ & Max. cost & Min. cost & $\% \mathrm{CV}$ & $\mathbf{C R}$ \\
\hline Tab Atenolol (12.5mg) & 2 & $21.95^{*}$ & $2.8^{*}$ & 683.93 & 7.84 \\
\hline Tab Atenolol (25 mg) & 16 & $37.9 *$ & $7.4^{*}$ & 412.16 & 5.12 \\
\hline Tab Atenolol (50 mg) & 19 & $53.09 *$ & $8.5^{*}$ & 524.59 & 6.25 \\
\hline Tab Atenolol (100 mg) & 9 & $76.7^{*}$ & $36^{*}$ & 113.06 & 2.13 \\
\hline Tab Bisoprolol (2.5mg) & 2 & 40 & 38.59 & 3.6538 & 1.04 \\
\hline Tab Bisoprolol (5mg) & 3 & 55 & 20.9 & 163.16 & 2.63 \\
\hline Tab Carvedilol (3.125 mg) & 8 & 23 & 9 & 155.56 & 2.56 \\
\hline Tab Carvedilol (6.25 mg) & 7 & 40 & 16 & 150 & 2.5 \\
\hline Tab Carvedilol (12.5 mg) & 8 & 50 & 30 & 66.667 & 1.67 \\
\hline Tab Carvedilol (25 mg) & 6 & 100 & 52 & 92.308 & 1.92 \\
\hline Tab Labetalol (100mg) & 3 & 120 & 29.57 & 305.82 & 4.06 \\
\hline Tab Propranolol (10mg) & 5 & 17 & 8.25 & 106.06 & 2.06 \\
\hline Tab Propranolol (20 mg) & 6 & 26 & 13.3 & 95.489 & 1.95 \\
\hline Tab Propranolol (40 mg) & 5 & 31 & 18.6 & 66.667 & 1.67 \\
\hline Tab Propranolol (80 mg) & 2 & 46.5 & 32.25 & 44.186 & 1.44 \\
\hline SR Tab Propranolol (40 mg) & 2 & 41 & 39 & 5.1282 & 1.05 \\
\hline Tab Metoprolol (25 mg) & 14 & 38 & 12 & 216.67 & 3.17 \\
\hline Tab Metoprolol (50 mg) & 12 & 56 & 18.5 & 202.7 & 3.03 \\
\hline Tab Metoprolol (100 mg) & 3 & 102 & 46.2 & 120.78 & 2.21 \\
\hline ER Tab Metoprolol (12.5 mg) & 2 & 33.25 & 27.5 & 20.909 & 1.21 \\
\hline ER Tab Metoprolol (25 mg) & 16 & 45 & 20 & 125 & 2.25 \\
\hline ER Tab Metoprolol (50 mg) & 17 & 70 & 30 & 133.33 & 2.33 \\
\hline ER Tab Metoprolol (100 mg) & 7 & 95 & 70 & 35.714 & 1.36 \\
\hline Cap Metoprolol (25 mg) & 3 & 42 & 10.67 & 293.63 & 3.94 \\
\hline Cap Metoprolol (50 mg) & 2 & 59 & 45 & 31.111 & 1.31 \\
\hline Tab Nebivolol (2.5 mg) & 8 & 52.5 & 32 & 64.063 & 1.64 \\
\hline Tab Nebivolol (5 mg) & 10 & 92.5 & 52 & 77.885 & 1.78 \\
\hline Tab Alphamethyl dopa (250mg) & 2 & 24.14 & 21.77 & 10.887 & 1.11 \\
\hline
\end{tabular}

(n-Number of brands, Max cost- Maximum cost per 10 drugs, Min cost -Minimum cost per 10 drugs, *- Cost per 14 drugs, \% CVPercentage cost variation, CR-Cost ratio, Tab -Tablet, SR Tab --Sustained release tablet, ER Tab - Extended release tablet, Cap Capsule).

ACE inhibitors, ARBs and Betablockers are commonly prescribed for the treatment of hypertension. Alpha methyl dopa is an important antihypertensive drug used to treat hypertension of pregnancy.

Hence wide range of cost discrepancies can pose problems in therapy due to non-adherence to treatment. Increased competition in the pharmaceutical market, rigid price control policies, promotion of good quality generic drugs etc. can reduce the price difference between different brands. There should be easy access to low priced, high quality drugs so as to ensure cost effective therapy.

\section{CONCLUSION}

This study highlights the huge price variation among different antihypertensive drugs which act through RAA axis modulation. Since Hypertension is a common disease requiring long term therapy, such price variations should not be entertained as they can lead to an unnecessary economic burden on Indian population. Hence, steps should be taken to sensitise the clinicians about the different brands of antihypertensive drugs and their prices so that rational use of drugs can be promoted keeping in mind the cost of these drugs also, thereby increasing patient compliance to therapy. Further, government can 
also frame policies to bring all life-saving and essential medicines under DPCO to ensure cost effective therapy.

Funding: No funding sources

Conflict of interest: None declared

Ethical approval: Not required

\section{REFERENCES}

1. Park K. Park's textbook of Preventive and Social Medicine. 23rd ed. Jabalpur. M/s Banarasidas Bhanot Publishers. 2015:372-5.

2. Kokiwar PR, Gupta SS, Durge PM. Prevalence of hypertension in a rural community in India. J Asso Physicians India. 2012;60:26-9.

3. Patel V, Chatterji S, Chisholm D, Ebrahim S, Gopalakrishna G, Mathers $\mathrm{C}$ et al. Chronic diseases and injuries in India. 2011;377:413-28.

4. Kamath L, Satish GR. Cost Variation Analysis of Antihypertensive Drugs Available in Indian Market: An Economic Perspective. Int $J$ Pharm Sci Res. 2016;7(5):2050-6.

5. Indrayan A. Epidemiology of hypertension. J Assoc Physicians India. 1994;42(2):175-6.

6. Mahal A, Karan A, Engelgau M. The Economic Implications of Non communicable Disease for India. Washington, DC: World Bank; 2010.

7. Sharma HL, Sharma KK. Principles of Pharmacology. 3rd ed. Paras Medical Publisher, Hyderabad, New Delhi. 2015:262-70.

8. Current Index of Medical specialities. UBM Medica India Private Limited, Bangalore. 2016;134:42-4.

9. Current Index of Medical specialities. UBM Medica India Private Limited, Bangalore. 2016;134:104-30.

10. Vihang S. Chawan, Kalpesh V. Gawand, Sagar V. Badwane. Cost analysis of oral hypolipidemic agents available in India. Int $\mathbf{J}$ Basic Clin Pharmacol. 2014;3(6):954-7.

11. Singh A, Kumar H Cost-analysis study of second generation antihistamines used in the treatment of allergic rhinitis in India. Int J Basic Clin Pharmacol. 2016;5(4):1228-33.

12. Ashwini V. Karve, Kanchan B. Chattar. Cost analysis study of oral antihypertensive agents available in Indian market. Int J Basic Clin Pharmacol. 2014; 3(3):479-83.

13. Lal A, Sharma ML. A calm look at the cost of drugs in psychiatric practice. Indian $\mathrm{J}$ Psychiat. 1992;34(1),18-20.

14. Akila L, Rani RJ. Cost analysis of different brands of antianginal drugs available in India. Int $\mathrm{J}$ Basic Clin Pharmacol. 2015;4:860-3.

15. Shukla AK, Agnihotri A. Cost analysis of antipsychotic drugs available in India. Int $\mathbf{J}$ Basic Clin Pharmacol. 2017 Mar;6(3):669-74.

16. Thomas M. Rational drug use and essential drug concept. In: Parthasarthi G, Nyfort-Hasen K, editors. A Textbook of Clinical Pharmacy Practice. 1st Edn. Himayatnagar, Hyderabad: Orient Longman; 2004:72-3.

17. Atal S, Deshmankar B, Nawaz SA. Cost analysis of commonly used drugs under price control in India: Assessing the effect of drug price control order on brand price variation. Int $\mathbf{J}$ Pharm Pharmceu Sci. 2016;8(4):315-21.

Cite this article as: Nair MK, Neha MS. Cost variation analysis of antihypertensive drugs acting through renin angiotensin aldosterone axis modulation. Int J Basic Clin Pharmacol 2017;6:10859. 